\title{
Lusioersily
}

\section{The potential use of rabies virus glycoproteinderived peptides to facilitate drug delivery into the central nervous system: a mini review}

Huey, R., \& Hawthorne, S. (2016). The potential use of rabies virus glycoproteinderived peptides to facilitate drug delivery into the central nervous system: a mini review. Journal of Drug Targeting, 1-7. https://doi.org/10.1080/1061186X.2016.1223676

Link to publication record in Ulster University Research Portal

Published in:

Journal of Drug Targeting

Publication Status:

Published online: 10/08/2016

DOI:

10.1080/1061186X.2016.1223676

\section{Document Version}

Author Accepted version

\section{General rights}

Copyright for the publications made accessible via Ulster University's Research Portal is retained by the author(s) and / or other copyright owners and it is a condition of accessing these publications that users recognise and abide by the legal requirements associated with these rights.

\section{Take down policy}

The Research Portal is Ulster University's institutional repository that provides access to Ulster's research outputs. Every effort has been made to ensure that content in the Research Portal does not infringe any person's rights, or applicable UK laws. If you discover content in the Research Portal that you believe breaches copyright or violates any law, please contact pure-support@ulster.ac.uk. 


\section{The potential use of rabies virus glycoprotein- derived peptides to facilitate drug delivery into the central nervous system: a mini review}

\section{Rachel Huey \& Susan Hawthorne}

To cite this article: Rachel Huey \& Susan Hawthorne (2016): The potential use of rabies virus glycoprotein-derived peptides to facilitate drug delivery into the central nervous system: a mini review, Journal of Drug Targeting, DOI: 10.1080/1061186X.2016.1223676

To link to this article: http://dx.doi.org/10.1080/1061186X.2016.1223676

Accepted author version posted online: 10

Aug 2016.

Published online: 10 Aug 2016.

Submit your article to this journal $₫$

à

View related articles $\asymp$

View Crossmark data $₫$ 


\section{The potential use of rabies virus glycoprotein-derived peptides to}

facilitate drug delivery into the central nervous system: a mini review

Rachel Huey \& Susan Hawthorne

School of Pharmacy and Pharmaceutical Sciences, Ulster University, Coleraine, United Kingdom

Address for correspondence: Dr Susan Hawthorne, School of Pharmacy and Pharmaceutical Sciences, Ulster University, Cromore Road, Coleraine, United Kingdom, BT52 1SA. E-mail: s.hawthorne@ulster.ac.uk 


\title{
The potential use of rabies virus glycoprotein-derived peptides to facilitate drug delivery into the central nervous system: a mini review
}

\begin{abstract}
Rabies virus glycoprotein (RVG), a 505 amino acid type-1 glycoprotein, is responsible for the neurotrophic nature of the rabies virus infection. Despite varying reports in the literature as to which receptor is ultimately responsible for interaction of RVG with the nervous system, there is a strong argument for major nicotinic acetylcholine receptor (nAChR) involvement. Peptide derivatives of RVG, such as rabies virus-derived peptide (RDP) and RVG-29 are emerging as promising targeting ligands for the delivery of therapeutics to the central nervous system (CNS). The neurotrophic nature of RVG and indeed its derivatives may be due to interaction with ubiquitous nAChRs principally, but also association with other neural cell-specific molecules such as neural cell adhesion molecule (NCAM). It is possible that nAChR-mediated uptake of RVG-derived peptides may serve as an attractive new approach for targeting drug delivery to the brain. Potential application of this type of drug delivery system extends to many diseases affecting the CNS, where specific and effective drug delivery is normally a challenging process
\end{abstract}

Keywords: rabies virus; glycoprotein; nicotinic acetylcholine receptor; peptide; targeted; delivery; central nervous system.

\section{Introduction}

The emergence of peptides derived from the rabies virus glycoprotein (RVG) as targeting ligands for drug delivery to the brain, have shown promise as an effective way of non-invasively overcoming the blood brain barrier (BBB) for targeted therapy. RVG forms the part of the rabies virus which is responsible for this neural interaction and is ultimately responsible for the highly neurotrophic nature of the rabies virus itself, as it is the only surface protein expressed on the viral envelope (Yan et al. 2002). Son et al. (2010) described RVG as a potential "magic bullet" for the targeting of genes to the 
brain. Rabies Virus-derived peptide (RDP) is a 39 amino acid derivative of residues 330-357 of RVG, which has been determined as an important nerve binding region (Fu et al., 2012). Due to this, RDP may retain the neurotrophic penetrating properties of RVG, acting as a facilitating ligand for neural cell entry of a conjugated payload. RDP has been utilised successfully to deliver therapeutic payloads to mouse brain in vivo (Fu et al. 2012), gaining effective entry into the central nervous system (CNS) and showing preferential accumulation in neural cells compared to non-neural, both in vitro and in vivo (Fu et al. 2013). Likewise, it has been peripherally conjugated to gold nanoclusters for non-invasive brain screening, due to its observed ability to specifically accumulate in neurons in vivo (Zhang \& Fu, 2015). Another derivative of RVG, RVG-29, allowed preferential accumulation of an Itraconazole payload in neural cells when conjugated to an albumin nanoparticle carrier (Chen et al. 2010). Furthermore, Liu et al. (2009) showed how nanoparticles coated with RVG-29 exhibited higher blood brain barrier (BBB) crossing efficiency than unmodified nanoparticles.

Thus far, there has been conflicting evidence in the literature as to which receptor is utilised in these synthetic peptide-neural interactions and indeed by the rabies virus glycoprotein itself. Fu et al. (2013) reports that the $\mathrm{GABA}_{(\mathrm{a})}$ receptor is responsible for RDP uptake in neural cells, however RVG-29 has been linked to both the $\mathrm{GABA}_{(\mathrm{b})}$ (Liu et al. 2009) and the nicotinic acetylcholine receptor (Lafon, $2005 \&$ Kumar et al. 2007). There has been a wealth of work invested over the past three decades in elucidating which receptor is responsible for the highly neurotrophic nature of the rabies virus infection. To date, the evidence available in the literature does not allow a definitive conclusion to be made regarding one particular receptor being 
responsible for rabies virus infectivity. Rather, it appears likely that other factors are involved and should be considered in the interaction with neural cells.

This review will consider the Rabies Virus glycoprotein and the different receptors with which it has been linked. Given the abundance of evidence that would indicate major nicotinic acetylcholine Receptor (nAChR) involvement, these receptors will also be discussed in regards to subtypes, typical structure and potential use as a target to mediate drug delivery into the central nervous system (CNS) through exploitation of the hypothetical interaction with RVG. It may be possible to utilise this interaction to deliver therapeutic agents non-invasively across the Blood Brain Barrier (BBB), with a view of treating neurodegenerative processes such as Parkinsons Disease (PD). It is therefore important that the receptor interaction of these RVG-derived peptides with neural cells is considered, if they are to be brought forward as potential drug-targeting moieties, to aid modelling and optimisation for in vivo success.

\section{Rabies virus}

The rabies virus is a pathogen of the mammalian nervous system, usually transferred from the saliva of an infected animal bite. The virus mostly affects motor neurons due to entry through the neuromuscular junction (NMJ) upon muscle infection (Lafon, 2005), however Lycke \& Tsiang (1987) indicated that peripheral sensory neurons are also likely to be infected even though the receptor responsible for uptake had yet to be identified. Lewis et al. (2000) studied rabies virus entry at the NMJ in chick nervemuscle co-cultures as a major site of entry into neurons and consequently the CNS. Further supporting the evidence of both motor and sensory neuron infection, this study 
also detailed how the virus travels throughout the nervous system via axonal retrograde transport. The retrograde pathway has been well established as the method of transport for the rabies virus as reviewed by Cherian et al. (2015) and indeed other neurotoxins, from distal infection sites, such as the tetanus toxin (Hislop et al. 2014). Incidentally, the Tet-1 peptide has been looked at as a targeting peptide for the CNS by Kwon et al. (2010), for the delivery of nucleic acids to neural cells in mice. This is another example of using an infective neuropeptide to direct a payload to a neural site, similar to the utilisation of RDP by Fu et al. (2012) \& (2013).

\section{Rabies virus glycoprotein (RVG)}

\section{$R V G$ and the nicotinic acetylcholine receptor}

RVG is a 505 amino acid type 1 membrane glycoprotein which is essential for infectivity of the Rabies Virus (Etessami et al. 2000), as it is responsible for attachment to target cells. RVG facilitates entry of the virus specifically into neurons at the NMJ through interaction with neural cell receptor molecules. It was first proposed by Lentz et al. (1982), that the acetylcholine receptor is a rabies virus receptor, based on the detection of the virus at or near acetylcholine sites in cultured chick myotubes. In this study, rhodamine-labelled alpha bungarotoxin ( $\alpha$-BTX) was used to detect the acetylcholine receptors, as this snake venom neurotoxin competitively binds to acetylcholine binding sites. Following a pre-incubation period, $\alpha$-BTX was able to significantly reduce the number of chick myotubes that became infected by rabies virus. The authors acknowledged that other molecules may be involved as infection could not be totally prevented by blocking the acetylcholine receptor, but these must be closely 
associated with acetylcholine binding sites. The detection of dense clusters of acetylcholine receptors at the tips of junctional folds may serve to enhance uptake at the NMJ, allowing eventual transport into the CNS.

Lentz et al. (1991) later compared a segment of RVG with the structure of a loop 2 domain of the curaremimetic neurotoxin, King Cobra Toxin b, and their subsequent interaction with the nAChR. The loop 2 of snake venom neurotoxins share a few invariant amino acid residues, which are consistent amongst them all. Interestingly, these sequences resemble a related homology with those found in RVG. Snake venom neurotoxin is able to bind at or near the acetylcholine binding site of nAChRs and consequently block ligand binding. Based on this, it was shown how manipulating these residues on both a 20 residue derivative of the King Cobra Toxin b and a 29 residue derivative of $\mathrm{RVG}$, displayed a similar response in that binding affinity was notably decreased, suggesting that these homologous sequences are responsible for interaction with the nAChR. It would appear that snake venom neurotoxins and RVG share the same binding mechanism to the $\mathrm{AChR}$, however an additional 10 amino acid sequence of RVG-29 peptide was identified which was important for maintaining a high binding affinity, unrelated to the neurotoxin structure. Similar work was carried out using the same neurotoxin by Zhan et al. (2010), where a short 20 residue neurotoxinpeptide was produced to facilitate drug delivery to the brain, via nAChRs, on endothelial cells of the BBB. By successfully enhancing the accumulation of coumarin6-loaded micelles in mouse brain, it was shown that this synthetic peptide bound with similar affinity to RVG derivative. This study inadvertently proved that a derivative of RVG binds to the neuronal-type nAChR, due to its inhibitory effect on $\alpha$-BTX, which binds to residues 173-204 of the alpha subunit on nAChRs (Gastka et al. 1996). These 
studies prove that RVG has a very strong connection with the nAChR due to the similarities with snake venom neurotoxin residues.

Sajjanar et al. (2015) found that synthesised peptides which have an homologous sequence with the $\alpha-1$ subunit of the nAChR were able to bind rabies virus and prevent infection in N2A neuroblastoma cells. Vigerelli et al. (2014) was also able to block rabies virus infection in BHK-21 (baby hamster kidney) cells using bufotenine, a tryptamine alkaloid from amphibian skin secretion. Based on the fact that other alkaloids such as nicotine and cytisine bind to the nicotinic receptor, the inhibitory effect of bufotenine on rabies virus would point toward this as the main surface receptor for cell entry. This recent research has come a long way from the work produced by Wunner et al. (1984), where rabies virus infection of non-neuronal BHK-21 lead to a conclusion that the nAChR was not essential for cell entry. Of course it is now known, and supported by the aforementioned work of Vigerelli et al. (2014), that these cells and indeed other non-neuronal cells may express the nicotinic receptor.

Kumar et al. (2007) used a derivative of RVG to successfully target siRNA to mouse brain in vivo and showed that it specifically bound to neural N2A cells over nonneural HeLa cells. In this study, the authors suspected that receptor mediated endocytosis was the mechanism of uptake across endothelial cells of the BBB.

Work by Castellanos et al. (2002) was based upon findings by Reagan \& Wunner, (1985), that cells not expressing the nAChR can still become infected by rabies virus. They aimed to assess the susceptibility of neuronal and non-neuronal cells, pretreated with nicotinic agonists, to rabies virus infection. The viruses used in this study 
would be from two different sources, one replicated in BHK-21 cells and the other from adult mouse brain. It was found that both neuronal (dorsal root ganglia) and nonneuronal (Schwann, fibroblasts etc.) cells became infected by both strains although neurotropism was observed, due to preferential accumulation in the neuronal cell type. At the time, the non-neuronal cell types were not believed to express nicotinic receptors and this lead to the conclusion that infectivity in non-neuronal cells was independent of this receptor, agreeing with previous research. It should be noted at the time of the work carried out by Wunner (1984) and by Reagan \& Wunner (1985), the method of $\mathrm{nAChR}$ detection was by alpha bungarotoxin binding. It is now known that alpha bungarotoxin does not bind to all nAChR subunits and more recently it has been shown that nAChRs are not restricted to neurons, in fact they are present throughout the CNS on microglia, (Shytle et al. 2004), brain endothelial cells (Abbruscato et al. 2002) and Schwann cells (Petrov et al. 2014). Taking this into consideration, there is a strong possibility that multiple cell types of neural origin can become infected with rabies virus via the nAChR and hence the neurotropism is not only due to neurons but glial cells too. It could be that cells of the central and peripheral nervous system express a higher number of, or a combination of, the right receptor molecules for glycoprotein binding. Care should therefore be taken when drawing conclusions, particularly when excluding nicotinic involvement. Castellanos et al. (2002) considered that rabies virus strains can exhibit different behaviour in vitro, in that multiple cell types can become infected, which does not reflect what actually happens in vivo.

The above findings certainly indicate that the nAChR plays a major role in Rabies Virus infection, mediated by the glycoprotein and supports nicotinic interaction with glycoprotein peptide-derivatives. The strong preference of the Rabies Virus to 
neural cells in vivo compared to other cells also expressing nAChRs, implies that other factors or molecules are also involved to varying degrees.

\section{Neural Cell Adhesion Molecule and Low Affinity Growth Factor Receptor}

The involvement of Neural Cell Adhesion Molecule (NCAM) in cell attachment and uptake of the rabies virus is somewhat ambiguous and subsequently passed over in comparison to the nAChR. Also known as CD56, it is a glycoprotein from the immunoglobulin (Ig) superfamily with functions in cell adhesion and signalling (Paratcha et al. 2003). NCAM plays a role in nervous system development by influencing cell migration, adhesion, neurite outgrowth and synaptic plasticity (Hubschmann et al. 2005). There has also been evidence to suggest that NCAM is required to maintain normal synaptic function at the NMJ following injury (Chipman et al. 2010).

Thoulouze et al. (1998) attempted to determine the role of NCAM in rabies virus infection, using NCAM-positive and NCAM-negative cells. It emerged that NCAMnegative cells transfected with the NCAM gene, showed enhanced susceptibility to the rabies virus infection and that blocking NCAM with a specific antibody and a heparin ligand reduced susceptibility. The authors believed this evidence would indicate that NCAM is a receptor for the rabies virus, certainly at the very least, it would suggest that NCAM plays a role in infection. Thoulouze et al. (1998) considered that the nicotinic receptor and NCAM may both be closely involved or even synergistic in nature. The independence of NCAM from the acetylcholine receptor is questionable, as the in vivo work from this same study showed that the brains of NCAM deficient mice were still 
infected by rabies virus and equally so in the hippocampus, albeit far less efficiently than in the NCAM-positive wild-type mice. Furthermore, NCAM deficiency does not prevent rabies-induced death in mice but only delays it. The fact that NCAM is not essential for infectivity means that although it seems to play an important role, it cannot be classified as a main receptor.

Given the expression of NCAM throughout the central and peripheral nervous system in astrocytes, neurons and non-myelinating Schwann cells, it is quite possible that NCAM forms part of a receptor complex which is responsible for the neurotropism of RVG at the neuromuscular junction (Lafon, 2005). Thoulouze et al. (2008), likened NCAM to the unidentified protein on BHK-21 cells, which binds to rabies virus, in work by Reagan \& Wunner, (1985). In addition to the nicotinic receptor, they detected rabies binding to an unknown protein, which similar to NCAM, was also a glycosylated integral membrane protein.

Hislop et al. (2014) described how RVG associated with three types of receptor in vitro. These were the aforementioned $\mathrm{nAChR}, \mathrm{NCAM}$ and the low-affinity nervegrowth factor/neurotrophin $\left(\mathrm{P} 75^{\mathrm{NTR}}\right)$ receptor. $\mathrm{P} 75^{\mathrm{NTR}}$ is from the tumour necrosis factor (TNF) family of receptors and although it is responsible for neurotophin signalling pathways, it has also been implicated in neurodegenerative processes. It was proposed by Tuffereau et al. (1998) that $\mathrm{P} 75^{\mathrm{NTR}}$ could be a receptor for the rabies virus, after detecting association with RVG in infected cell lines in vitro. Almost a decade later, following doubts over association in vivo, Tuffereau et al. (2007) revisited this work and concluded that $\mathrm{P} 75^{\mathrm{NTR}}$ was not essential for rabies virus infection. It was also 
detailed that $\mathrm{P} 75^{\mathrm{NTR}}$ expression alone, was not sufficient enough to infect cells in vivo and other factors are almost certainly implicated.

It should be noted that the interaction of RVG with $\mathrm{P} 75^{\mathrm{NTR}}$ as accounted by Hislop et al. (2014), was in a mouse hybrid cell line of neuroblastoma and spinal cord cells. This model was not representative of the in vivo NMJ and there appears to be no in vivo evidence of $\mathrm{P} 75^{\mathrm{NTR}}$ presence at the NMJ (Lafon, 2005). Whether or not NCAM and $\mathrm{P} 75^{\mathrm{NTR}}$ play a key role in vivo or merely an accessory role in the neurotropism of RVG remains unclear, as conclusions drawn from in vitro results have deviated from in vivo behaviour.

\section{Nicotinic Acetylcholine Receptors- structure and subunit expression}

There are two principal subtypes of Acetylcholine receptor in the human body, the metabotropic muscarinic acetylcholine receptor and the ionotropic nicotinic acetylcholine receptor (nAChR). Both of these groups are activated by the endogenous ligand, acetylcholine, at neuronal and non-neuronal sites. The muscarinic subtype has been distinguished byits typical activation by muscarine, the mushroom toxin from Amanita muscaria, whereas the nicotinic subclass is prominently activated by the exogenous ligand, nicotine.

nAChRs are a family of cationic channels and along with the muscarinic subtype, 5-Hydroxytryptamine (serotonin) receptors and $\gamma$-aminobutyric acid (GABA) $\mathrm{A} / \mathrm{C}$ receptors, they form part of the Cys-loop gene superfamily commonly known as 
ligand-gated ion channels (Gotti \& Clementi, 2004 \& Dunckley \& Lukas, 2006). They have been classically further subdivided into neuronal-type nAChRs and muscle-type nAChRs, however more recently there has been evidence of "neuronal-type" nAChRs in other areas of the body besides the nervous system. Early studies and initial purification of this receptor was possible due to observations made of the Torpedo electric organ, where dense areas of nAChRs in the tail of these electric rays played a role in the stinging of prey. Alongside this, studies with $\alpha$-Bungarotoxin $(\alpha-B T X)$, a venom from the Taiwanese Krait (Bungarus multicinctus), competitively bound nAChRs at the neuromuscular junction, causing paralysis (Albuquerque et al. 1997).

Neuronal-type nAChRs exist as homopentameric or heteropentameric subtypes. This means they are typically composed of 5 subunits surrounding a central pore, as depicted in Figure 1 (a). Thus far, the subunits which have been identified in mammalian neuronal-type nAChRs are nine $\alpha(\alpha 1-\alpha 9)$ and three $\beta(\beta 2-\beta 4)$ subunits. (Hadaddian et al. 2008 \& Quik \& Wanacott, 2011). The homopentameric arrangement, also known as $\alpha$-Bungarotoxin sensitive, is composed of five identical $\alpha 7$ subunits and so five identical agonist binding sites. In the human central and peripheral nervous system, $\alpha 7$ homomeric receptors are one of the most commonly found, particularly in neurons of hippocampal origin. It is possible that $\alpha 8$ and $\alpha 9$ subunits also compose these homomeric receptors but so far the $\alpha 8$ subunit has not been identified in humans and the $\alpha 9$ subunit has presently not been isolated in neurons (Gotti \& Clementi, 2004).

The heteropentameric arrangement is generally in the stoichiometry arrangement of $2 \alpha 3 \beta^{*}$; where * signifies the possibility of a different additional $\alpha$ subunit in the complex (Patterson \& Nordberg, 2000). These receptors will have two agonist binding 
sites, between $\alpha$ and $\beta$ units, both of which must be occupied for activation of the receptor. These are also known as $\alpha$-Bungarotoxin insensitive but show a higher affinity in agonist binding compared to their homomeric counterparts. Although the $\alpha 2$, $\alpha 3, \alpha 4, \alpha 6, \beta 2$ and $\beta 4$ subunits play a role in binding and may be co-expressed by a particular neuron, only a few combinations may actually be formed. This also had led to the conclusion that $\alpha 5$ and $\beta 3$ subunits merely play a supportive role rather than being involved in agonist binding (Gotti \& Clementi, 2006).

The major nAChR subtypes in the mammalian central nervous system are $\alpha 4 \beta 2 *$ and $\alpha 7^{*}$, comprising approximately $90 \%$. The structure of both these receptor subtypes and their respective binding sites are shown in Figure 1 (a). Other brain areas such as the striatum, contain dopaminergic neurons which also widely express the $\alpha 6 \beta 3^{*}$ subtype. Subsequently, the expression of these receptors is diminished in Parkinson's disease, due to the loss of dopaminergic neurons (Warpman et al. 1998 \& Posadas et al. 2013). In the Central Nervous System (CNS), nAChRs are widely expressed, as they form a major part of the cholinergic transmission pathways in the brain and peripheral ganglia. Their role in pre-synaptic neurotransmitter release and post-synaptic transmission means that central innervation gives rise to many different functions. These include cognition, reward, pain processing, arousal and motor activity (Gotti \& Clementi, 2006). These functions of nAChRs depend on brain location and indeed subunit composition.

It was previously mentioned, neuronal-type nAChRs may also be found on other body sites in non-neuronal roles. Table 1 details the particular subunits which have been detected thus far in the brain but also within other body systems, not involved in 
synaptic transmission. Lymphoid cells of the thymus (Navaneetham et al. 1997), peripheral macrophages (De Simone et al. 2005), lung epithelial cells (Maus et al. 1998), skin keratinocytes (Grando et al. 1995, 1996) and vascular endothelial cells (Wang et al. 2001) all express subunits which are capable of assembling functional nAChRs, which are thought to have roles in apoptosis and proliferation (Conti-Fine et al. 2000 \& Egleton et al. 2008). Sharma \& Vijayaraghavan (2002) reviewed the nicotinic subtype expression in these non-neural tissue types and in agreement with the data presented in Table 1, there is widespread indication that the $\alpha 3, \alpha 5, \alpha 7, \beta 2$ and $\beta 4$ subunits are the most common subtypes found outside the central nervous system. At the interface between the central nervous system and the blood circulation, there has been detection of nAChR subunits on brain endothelial cells of the blood brain barrier. These cells specifically express the $\alpha 3, \alpha 5, \alpha 7, \beta 2$ and $\beta 3$ subunits, as reported by Abbruscato et al. (2002) in an immunoreactivity assay. Fischer et al. (1997) detected the presence of the $\alpha 7$ subunit from nAChRs of neuronal origin in rat dennervated adult muscle. The role of these receptors in a non-neural capacity is unclear, although Gotti \& Clementi (2004) speculate about a gene expression role by altering calcium ion influx. On the contrary, muscle-type nAChRs are confined to muscle only (Albuquerque et al. 2009). In the muscle-type nAChRs, subunit composition of the receptor is not limited to only $\alpha$ and $\beta$ subunits like those of neuronal origin. They are comprised of five different subunits- $\alpha 1, \beta 1, \delta, \gamma$ and $\varepsilon$. Typical muscle-type nicotinic acetylcholine receptor subunit composition is shown in Figure 1 (b), where subunits are usually in the ratio of 2:1:1:1 (Galzi \& Changeux, 1995 and Patterson \& Nordberg, 2000). 
Castellanos et al. (1997) found that mecamylamine and d-turbocurarine were the only nicotinic ligands of many, capable of reducing the ratios of rabies-infected neurons from primary culture. Conversely, at a similar time, Lentz et al. (1997) found that only $\alpha$ BTX, but neither mecamylamine nor d-turbocurarine, was capable of reducing rabies virus infection in IMR-32 neuroblastoma cells. Castellanos et al. (2002) later explained that neuronal cells from primary culture may express different subunits to individual cell lines, offering an explanation for this inconsistency in results between the two studies involving nicotinic blocking agents. This explanation suggested that different nAChR subunit expression may potentially cause different binding affinities of the receptor with ligands such as $\alpha$-BTX. The same may be true for RVG, in that it may only be able to bind to certain nAChR subunits.

\section{Potential applications of RVG-nAChR interaction}

The challenge of finding an effective treatment for neurodegenerative disorders is complicated by the difficulties posed by the BBB. It has been well established over many years how difficult drug delivery to the central nervous system (CNS) can be, thus causing treatments to be of perceived limited efficacy in vivo. The specialised structure of the $\mathrm{BBB}$ is responsible for preventing the free passage of blood components from the general circulation into the CNS. Tight junctions composed of membrane proteins such as occludins and claudins between brain endothelial cells, prevent blood borne substances diffusing through paracellular space. This means only small (<400 Da), hydrophobic molecules such as oxygen and carbon dioxide can pass freely across the barrier (Ballabh et al. 2003). Consequently, large or hydrophilic molecules require transcellular transport via energy-dependent mechanisms such as carrier mediated 
transport. The presence of p-glycoprotein efflux transporters together with low endocytosis (Wilhelm, 2011), makes drug delivery very difficult and ultimately is responsible for multi-drug resistance (Zlockivoc, 2008).

New strategies are required to conquer the problems of the BBB. One of these new methods in recent times has been to exploit molecules which are known to freely enter the CNS. Nicotine is the most well-known exogenous agonist of nAChRs due to its addictive nature through tobacco smoking. In fact, nicotinic activation has shown to promote neuronal survival and displayed neuroprotective properties in both in vitro and in vivo studies. There is sufficient evidence to suggest that disruption in transmission via nAChRs in the brain plays a significant role in age-related diseases. (Gotti et al., 2006). This has led to the suggestion that nicotine and nicotinic drugs may be effective as a possible treatment for neurodegenerative disorders such as Parkinson's disease (PD) and Alzheimer's disease (AD).

Dunckley \& Lukas (2006), report changes in gene expression in SH-SY5Y neuroblastoma cells following nicotinic exposure. In this report, they discuss how some nAChR subtypes might be involved in intracellular signaling pathways which have certainly more than one type of effect. In other words, one receptor may modulate multiple pathways, such is the complexity of cholinergic transmission. This leads to a lack of efficacy and non-specificity, possibly explaining why nicotine and nicotinic drugs have not lived up to their clinical potential as a treatment for neurodegenerative disorders such as PD and AD. According to Gotti \& Clementi (2004), it is the $\alpha 4$ and $\alpha 6$ subunits that play a major role in dopamine release in the nigrostriatal pathway and the lack of selective activation by nicotinic agonists counters any desirable effects. This essentially rules out nicotinic treatment as a viable option in PD. In addition to this, the 
use of knockout mice have shown that nicotinic receptor subtypes in the brain are not essential for survival, but play a major part in the control of more complex behaviours. This supports the idea that their dysregulation is responsible in part for neural diseases such as schizophrenia, epilepsy, AD and PD (Gotti et al. 2006).

Although nicotine has not proved a viable option for the treatment of neurodegenerative disorders, this does not rule out the possibility of targeting the nAChR for a therapeutic purpose. Instead of activating these receptors to achieve a favourable biological response through signalling pathways, there is potential to use them as a means of improving entry and delivery of a therapeutic payload to the brain.

Due to the presence of neuronal nicotinic acetylcholine receptors at the NMJ, it is possible that an RVG derivative may be utilised to target the delivery of drugs or drug carriers into the CNS, overcoming many problems of BBB crossing and neural cell entry. Lentz et al. (1990) established that the rabies virus can bind to residues 173-204 of the $\alpha 1$ subunit of muscle-type nAChRs present at the neuromuscular junction. This evidence was backed up by Gastka et al. (1996), where rabies virus bound to the $\alpha 1$ subunit of muscle-type nAChR detected by Western Blotting. Here the authors concluded that the rabies virus shares a binding site with $\alpha$-BTX, a competitive inhibitor of acetylcholine, which was able to inhibit rabies virus binding with the $\alpha 1$ subunit. Interestingly the aforementioned work by Lentz et al. (1990), also found that that the virus was able to bind to the $\alpha-3$ subunit, confirming that the rabies virus does in fact bind to neuronal-type nAChRs as well as muscle-type. It is however currently acknowledged that neuronal-type nAChRs are present at the NMJ too, meaning that additional subunits such as $\alpha 7$ are very likely to play a role in RVG binding and explain the ability of the rabies virus to traverse the CNS so readily. 
RDP has been taken up by SH-SY5Y neuroblastoma cells in vitro but has also shown the capability to facilitate the delivery of therapeutics to mouse brain in vivo (Fu et al., 2013). If the $\mathrm{nAChR}$ was responsible for RDP uptake, in order to cross the BBB it would have to bind to either the $\alpha 3, \alpha 5$ or $\alpha 7$ subunit as shown in Table 1. Likewise, SH-SY5Y neuroblastoma cells are known to express both the $\alpha 7$ and a3 subunits (Dunckley \& Lukas, 2006), also shown in Table 1. It could therefore be postulated that RDP has the potential to bind to more than one subtype of nAChR. However, to date, the major receptor responsible for RDP cellular uptake has not been elucidated for certain and hence the most important subtypes for brain entry have not yet been identified.

Taking advantage of the neurotrophic properties of RVG in vivo and the ubiquitous nature of nAChRs in the CNS may provide the basis for new brain targeting mechanisms, such as the work already mentioned, by Fu et al. (2012 \& 2013) and Zhang \& Fu (2015) on rabies virus-derived peptide (RDP)-conjugates. Mazarakis et al. (2001), proposed that viral envelope glycoproteins such as RVG, may be utilised as a new approach for gene therapy, with a view of treating neurodegenerative disorders such as Parkinson's, Alzheimer's and Motor-Neuron diseases. Lewis et al. (2000) confirmed the entry of rabies virus to the CNS via axonal retrograde transport and using endosomal tracers, found evidence of receptor-virus endocytic uptake at the NMJ. This is possibly the mechanism by which RVG-conjugated vectors successfully delivered genetic material to motor neurons of rat spinal cord, hippocampus and striatum after intramuscular administration at the gastrocnemius muscle (Mazarakis et al. 2001). This study also showed that the vesicular stomatitis virus glycoprotein (VSV-G) was unable to target the vector to the CNS from the distal infection site. RVG therefore, shows 
better targeting capabilities to the CNS than VSV-G, allowing for specific accumulation of a therapeutic payload.

St. Pierre et al. (2011) used a mouse neuroblastoma cell line (MNA) to detect RVG association with the endocytic pathway. RVG peptide derivatives such as RVG-29 and RDP are thought to gain cell entry via the endocytic pathway also. Liu et al. (2009) reported that RVG-29 conjugated nanoparticles enter brain capillary endothelial cells via both clathrin and calveolae-dependent receptor-mediated endocytosis mechanisms. Fu et al. (2013) related findings to further support the receptor-mediated endocytosis pathway as the main mechanism of RVG-derived peptide cell penetration, when it was shown that the endocytosis inhibitor, colchicine, was able to significantly prevent uptake of an RDP conjugate in SHSY5Y neuroblastoma cells. Fu et al. hypothesised that clathrin-dependent endocytosis was most likely, regardless of whether the target surface receptor is the nAChR or GABA (A) receptor, as it is the most common endocytosis mechanism for both (Fu et al., 2013). To date, there is no solid evidence of the type of endocytosis involved in the cellular uptake of RDP. A hypothetical diagram showing the proposed mechanism of uptake involving the clathrin-mediated endocytosis pathway is shown in Figure 2. It is therefore likely that RVG and its derivatives are internalised by a receptor-mediated endocytosis mechanism. The identity of this receptor is quite likely to be the nAChR, with a strong possibility of additional mechanisms such as association with NCAM, although areas of uncertainty exist. This is particularly true for the new RVG-derivatives such as RDP, where the GABA receptor has also been proposed as a potential candidate for binding. 
The promise of these rabies virus glycoprotein-derived peptides for selectively targeting the CNS, could provide an exciting new way of non-invasively overcoming the challenges of the $\mathrm{BBB}$ and delivering a therapeutic cargo to the brain or spinal cord. Given the natural preference for neural cells in vivo and the lack of immune response reported thus far, the foundation for future work exists, to develop potential drug delivery systems for the fight against neurodegenerative disorders which are notoriously difficult to treat. 


\section{References}

Abbruscato, T.J., Lopez, S.P., Mark, K.S., Hawkins, B.T. and Davis, T.P. (2002) Nicotine and cotinine modulate cerebral microvascular permeability and protein expression of ZO-1 through nicotinic acetylcholine receptors expressed on brain endothelial cells. Journal of Pharmaceutical Sciences, 91(12), 2525-2538.

Albuquerque, E., Alkondon, M., Pereira, E., Castro, N., Schrattenholz, A., Barbosa, C., BonfanteCabarcas, R., Aracava, Y., Eisenberg, H. and Maelicke, A. (1997) Properties of neuronal nicotinic acetylcholine receptors: Pharmacological characterization and modulation of synaptic function. Journal of Pharmacology and Experimental Therapeutics, 280(3), 1117-1136.

Albuquerque, E.X., Pereira, E.F.R., Alkondon, M. and Rogers, S.W. (2009) Mammalian Nicotinic Acetylcholine Receptors: From Structure to Function. Physiological Reviews, 89(1), 73-120.

Ballabh, P., Braun, A. and Nedergaard, M. (2004) The blood-brain barrier: an overview - Structure, regulation, and clinical implications. Neurobiology of Disease, 16(1), 1-13.

Castaneda-Castellanos, D.R., Castellanos, J.E. and Hurtado, H. (2002) Differential use of the nicotinic receptor by rabies virus based upon substrate origin. Journal of Neurovirology, 8(2), 150-154.

Castellanos, J.E., Castaneda, D.R., Velandia, A.E. and Hurtado, H. (1997) Partial inhibition of the in vitro infection of adult mouse dorsal root ganglion neurons by rabies virus using nicotinic antagonists. Neuroscience Letters, 229(3), 198-200. 
Chen, W., Zhan, C., Gu, B., Meng, Q., Wang, H., Lu, W. and Hou, H. (2011) Targeted brain delivery of itraconazole via RVG29 anchored nanoparticles. Journal of Drug Targeting, 19(3), 228-234.

Cherian, S., Singh, R., Singh, A. (2015) Rabies Glycoprotein: A Benefit to the Virus, us or both? Journal of Veterinary Sciences, 1(1), 1-9.

Chipman, P.H., Franz, C.K., Nelson, A., Schachner, M. and Rafuse, V.F. (2010) Neural cell adhesion molecule is required for stability of reinnervated neuromuscular junctions. European Journal of Neuroscience, 31(2), 238-249.

Conti-Fine, B.M., Navaneetham, D., Lei, S. and Maus, A.D.J. (2000) Neuronal nicotinic receptors in non-neuronal cells: new mediators of tobacco toxicity? European Journal of Pharmacology, 393(1-3), 279-294.

Court, J.A., Martin-Ruiz, C., Graham, A. and Perry, E. (2000) Nicotinic receptors in human brain: topography and pathology. Journal of Chemical Neuroanatomy, 20(3-4), 281-298.

Dunckley, T. and Lukas, R.J. (2006) Nicotinic modulation of gene expression in SHSY5Y neuroblastoma cells. Brain Research, 1116, 39-49.

Egleton, R.D., Brown, K.C. and Dasgupta, P. (2008) Nicotinic acetylcholine receptors in cancer: multiple roles in proliferation and inhibition of apoptosis. Trends in Pharmacological Sciences, 29(3), 151-158.

Etessami, R., Conzelmann, K.K., Fadai-Ghotbi, B., Natelson, B., Tsiang, H. and Ceccaldi, P.E. (2000) Spread and pathogenic characteristics of a G-deficient rabies virus recombinant: an in vitro and in vivo study. Journal of General Virology, 81, 2147-2153. 
Fischer, U., Reinhardt, S., Albuquerque, E.X. and Maelicke, A. (1999) Expression of functional alpha 7 nicotinic acetylcholine receptor during mammalian muscle development and denervation. European Journal of Neuroscience, 11(8), 2856-2864.

Fu, A.L., Wang, Y.L., Zhan, L.P. and Zhou, R.M. (2012) Targeted Delivery of Proteins into the Central Nervous System Mediated by Rabies Virus Glycoprotein-Derived Peptide. Pharmaceutical Research, 29(6), 1562-1569.

Fu, A.L., Zhao, Z.Z., Gao, F.Y. and Zhang, M.M. (2013) Cellular Uptake Mechanism and Therapeutic Utility of a Novel Peptide in Targeted-Delivery of Proteins into Neuronal Cells. Pharmaceutical Research, 30(8), 2108-2117.

Galzi, J.L. and Changeux, J.P. (1995) Neuronal Nicotinic Receptors - MolecularOrganization and Regulations. Neuropharmacology, 34(6), 563-582.

Gastka, M., Horvath, J. and Lentz, T.L. (1996) Rabies yirus binding to the nicotinic acetylcholine receptor alpha subunit demonstrated by virus overlay protein binding assay. Journal of General Virology, 77, 2437-2440.

Gotti, C. and Clementi, F. (2004) Neuronal nicotinic receptors: from structure to pathology. Progress in Neurobiology, 74(6), 363-396.

Gotti, C., Zoli, M. and Clementi, F. (2006) Brain nicotinic acetylcholine receptors: native subtypes and their relevance. Trends in Pharmacological Sciences, 27(9), 482491.

Grando, S.A., Horton, R.M., Mauro, T.M., Kist, D.A., Lee, T.X. and Dahl, M.V. (1996) Activation of Keratinocyte Nicotinic Cholinergic Receptors Stimulates Calcium Influx 
and Enhances Cell Differentiation. Journal of Investigative Dermatology, 107(3), 412418.

Grando, S.A., Zelickson, B.D., Kist, D.A., Weinshenker, D., Bigliardi, P.L., Wendelschafer-Crabb, G., Kennedy, W.R. and Dahl, M.V. (1995) Keratinocyte Muscarinic Acetylcholine Receptors: Immunolocalization and Partial Characterization. Journal of Investigative Dermatology, 104(1), 95-100.

Haddadian, E.J., Cheng, M.H., Coalson, R.D., Xu, Y. and Tang, P. (2008) In Silico Models for the Human alpha 4 beta 2 Nicotinic Acetylcholine Receptor. Journal of Physical Chemistry B, 112(44), 13981-13990.

Hislop, J.N., Islam, T.A., Eleftheriadou, I., Carpentier, D.C.J., Trabalza, A., Parkinson, M., Schiavo, G. and Mazarakis, N.D. (2014) Rabies Virus Envelope Glycoprotein Targets Lentiviral Vectors to the Axonal Retrograde Pathway in Motor Neurons. Journal of Biological Chemistry, 289(23), 16148-16163.

Hubschmann, M.V., Skladchikova, G., Bock, E. and Berezin, V. (2005) Neural cell adhesion molecule function is regulated by metalloproteinase-mediated ectodomain release. Journal of Neuroscience Research, 80(6), 826-837.

Kumar, P., Wu, H., McBride, J.L., Jung, K., Kim, M.H., Davidson, B.L., Lee, S.K., Shankar, P. and Manjunath, N. (2007) Transvascular delivery of small interfering RNA to the central nervous system. Nature, 448(7149), 39-43.

Kuo, Y., Lucero, L., Michaels, J., DeLuca, D. and Lukas, R.J. (2002) Differential expression of nicotinic acetylcholine receptor subunits in fetal and neonatal mouse thymus. Journal of Neuroimmunology, 130(1-2), 140-154. 
Kwon, E.J., Lasiene, J., Jacobson, B.E., Park, I., Horner, P.J. and Pun, S.H. (2010)

Targeted nonviral delivery vehicles to neural progenitor cells in the mouse subventricular zone. Biomaterials, 31(8), 2417-2424.

Lafon, M. (2005) Rabies virus receptors. Journal of NeuroVirology, 11(1), 82-87.

Lentz, T., Burrage, t., Smith, A., Crick, j. And Tignor, G. (1982) Is the AcetylcholineReceptor a Rabies Virus Receptor. Science, 215(4529), 182-184.

Lentz, T.L. (1990) Rabies virus binding to an acetylcholine receptor alpha-subunit peptide. Journal of Molecular Recognition, 3(2), 82-88.

Lentz, T.L. (1991) Structure-Function-Relationships of Curaremimetic Neurotoxin Loop-2 and of a Structurally Similar Segment of Rabies Virus Glycoprotein in their Interaction with the Nicotinic Acetylcholine-Receptor. Biochemistry, 30(45), 1094910957.

Lentz, T.L., Fu, Y.G. and Lewis, P. (1997) Rabies virus infection of IMR-32 human neuroblastoma cells and effect of neurochemical and other agents. Antiviral Research, 35(1), 29-39.

Lewis, P., Fu, Y.G. and Lentz, T.L. (2000) Rabies virus entry at the neuromuscular junction in nerve-muscle cocultures. Muscle \& Nerve, 23(5), 720-730.

Liu, Y., Huang, R., Han, L., Ke, W., Shao, K., Ye, L., Lou, J. and Jiang, C. (2009) Brain-targeting gene delivery and cellular internalization mechanisms for modified rabies virus glycoprotein RVG29 nanoparticles. Biomaterials, 30(25), 4195-4202. 
Lycke, E. and Tsiang, H. (1987) Rabies Virus-Infection of Cultured Rat Sensory Neurons. Journal of Virology, 61(9), 2733-2741.

Maus, A.D.J., Pereira, E.F.R., Karachunski, P.I., Horton, R.M., Navaneetham, D., Macklin, K., Cortes, W.S., Albuquerque, E.X. and Conti-Fine, B.M. (1998) Human and rodent bronchial epithelial cells express functional nicotinic acetylcholine receptors. Molecular Pharmacology, 54(5), 779-788.

Mazarakis, N.D., Azzouz, M., Rohll, J.B., Ellard, F.M., Wilkes, F.J., Olsen, A.L., Carter, E.E., Barber, R.D., Baban, D.F., Kingsman, S.M., Kingsman, A.J., O'Malley, K. and Mitrophanous, K.A. (2001) Rabies virus glycoprotein pseudotyping of lentiviral vectors enables retrograde axonal transport and access to the nervous system after peripheral delivery. Human Molecular Genetics, 10(19), 2109-2121.

Navaneetham, D., Penn, A., Howard, J. and ContiFine, B.M. (1997) Expression of the alpha 7 subunit of the nicotinic acetylcholine receptor in normal and myasthenic human thymuses. Cellular and Molecular Biology, 43(3), 433-442.

Nguyen, V.T., Ndoye, A. and Grando, S.A. (2000) Novel Human $\alpha 9$ Acetylcholine Receptor Regulating Keratinocyte Adhesion is Targeted by Pemphigus Vulgaris Autoimmunity. The American Journal of Pathology, 157(4), 1377-1391.

Paratcha, G., Ledda, F. and Ibáñez, C.F. (2003) The Neural Cell Adhesion Molecule NCAM Is an Alternative Signaling Receptor for GDNF Family Ligands. Cell, 113(7), 867-879.

Paterson, D. and Nordberg, A. (2000) Neuronal nicotinic receptors in the human brain. Progress in Neurobiology, 61(1), 75-111. 
Petrov, K.A., Girard, E., Nikitashina, A.D., Colasante, C., Bernard, V., Nurullin, L., Leroy, J., Samigullin, D., Colak, O., Nikolsky, E., Plaud, B. and Krejci, E. (2014) Schwann Cells Sense and Control Acetylcholine Spillover at the Neuromuscular Junction by alpha 7 Nicotinic Receptors and Butyrylcholinesterase. Journal of Neuroscience, 34(36), 11870-11883.

Posadas, I., Lopez-Hernandez, B. and Cena, V. (2013) Nicotinic Receptors in Neurodegeneration. Current Neuropharmacology, 11(3), 298-314.

Quik, M. and Wonnacott, S. (2011) alpha 6 beta $2 *$ and alpha 4 beta $2 *$ Nicotinic Acetylcholine Receptors As Drug Targets for Parkinson's Disease. Pharmacological Reviews, 63(4), 938-966.

Reagan, K.J. and Wunner, W.H. (1985) Rabies Virus Interaction with various CellLines is Independent of the Acetylcholine-Receptor-Brief Report. Archives of Virology, 84(3-4), 277-282.

Sajjanar, B., Saxena, S., Bisht, D., Singh, A.K., Manjunatha Reddy, G.B., Singh, R., Singh, R.P. and Kumar, S. (2015) Effect of nicotinic acetylcholine receptor alpha 1 (nAChR $\alpha 1$ ) peptides on rabies virus infection in neuronal cells. Neuropeptides,

Sharma, G. and Vijayaraghavan, S. (2002) Nicotinic receptor signaling in nonexcitable cells. Journal of Neurobiology, 53(4), 524-534.

Shytle, R.D., Mori, T., Townsend, K., Vendrame, M., Sun, N., Zeng, J., Ehrhart, J., Silver, A.A., Sanberg, P.R. and Tan, J. (2004) Cholinergic modulation of microglial activation by alpha-7 nicotinic receptors. Journal of Neurochemistry, 89(2), 337-343. 
Son, S., Hwang, D.W., Singha, K., Jeong, J.H., Park, T.G., Lee, D.S. and Kim, W.J. (2011) RVG peptide tethered bioreducible polyethylenimine for gene delivery to brain. Journal of Controlled Release, 155(1), 18-25.

St. Pierre, C.A., Leonard, D., Corvera, S., Kurt-Jones, E.A. and Finberg, R.W. (2011) Antibodies to cell surface proteins redirect intracellular trafficking pathways. Experimental and Molecular Pathology, 91(3), 723-732.

Thoulouze, M., Lafage, M., Schachner, M., Hartmann, U., Cremer, H. and Lafon, M. (1998) The neural cell adhesion molecule is a receptor for rabies virus. Journal of Virology, 72(9), 7181-7190.

Tuffereau, C., Benejean, J., Roque-Alfonso, A., Flamand, A. and Fishman, M. (1998) Neuronal cell surface molecules mediate specific binding to rabies virus glycoprotein expressed by a recombinant baculovirus on the surfaces of lepidopteran cells. Journal of Virology, 17(24), 7250-7259.

Tuffereau, C., Schmidt, K., Langevin, C., Lafay, F., Dechant, G. and Koltzenburg, M. (2007) The rabies virus glycoprotein receptor p75(NTR) is not essential for rabies virus infection. Journal of Virology, 81(24), 13622-13630.

Vigerelli, H., Sciani,J.M., Jared, C., Antoniazzi, M.M., Medeiros Caporale, G.M., Rodrigues da Silva,Andrea de Cassia and Pimenta, D.C. (2014) Bufotenine is able to block rabies virus infection in BHK-21 cells. Journal of Venomous Animals and Toxins Including Tropical Diseases, 20, 45.

Wang, Y., Pereira, E.F.R., Maus, A.D.J., Ostlie, N.S., Navaneetham, D., Lei, S., Albuquerque, E.X. and Conti-Fine, B.M. (2001) Human Bronchial Epithelial and 
Endothelial Cells Express a7 Nicotinic Acetylcholine Receptors. Molecular

Pharmacology, 60(6), 1201-1209.

Warpman, U., Friberg, L., Gillespie, A., Hellstrom-Lindahl, E., Zhang, X. and Nordberg, A. (1998) Regulation of nicotinic receptor subtypes following chronic nicotinic agonist exposure in M10 and SH-SY5Y neuroblastoma cells. Journal of Neurochemistry, 70(5), 2028-2037.

Wilhelm, I., Fazakas, C. and Krizbai, I.A. (2011) In vitro models of the blood-brain barrier. Acta Neurobiologiae Experimentalis, 71(1), 113-128.

Wunner, W.H., Reagan, K.J. and Koprowski, H. (1984) Characterization of Saturable Binding-Sites for Rabies Virus. Journal of Virology, 50(3), 691-697.

Yan, X.Z., Mohankumar, P.S., Dietzschold, B., Schnell, M.J. and Fu, Z.F. (2002) The rabies virus glycoprotein determines the distribution of different rabies virus strains in the brain. Journal of Neurovirology, 8(4), 345-352.

Zhan, C., Yan, Z., Xie, C. and Lu, W. (2010) Loop 2 of Ophiophagus hannah Toxin b Binds with Neuronal Nicotinic Acetylcholine Receptors and Enhances Intracranial Drug Delivery. Molecular Pharmaceutics, 7(6), 1940-1947.

Zhang, E. and Fu, A. (2015) A new strategy for specific imaging of neural cells based on peptide-conjugated gold nanoclusters. International Journal of Nanomedicine, 10, 2115-2124.

Zlokovic, B.V. (2008) The blood-brain barrier in health and chronic neurodegenerative disorders. Neuron, 57(2), 178-201. 


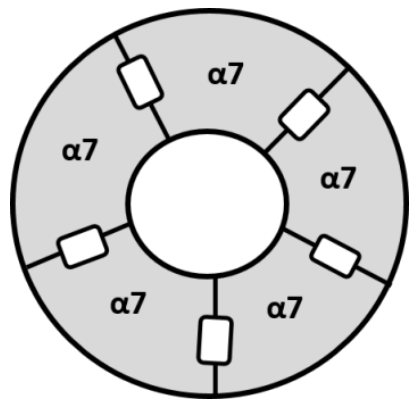

a. (i)

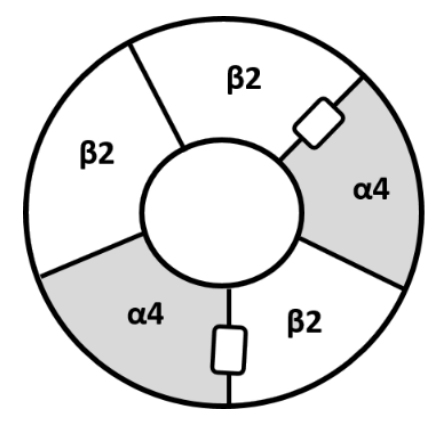

(ii)

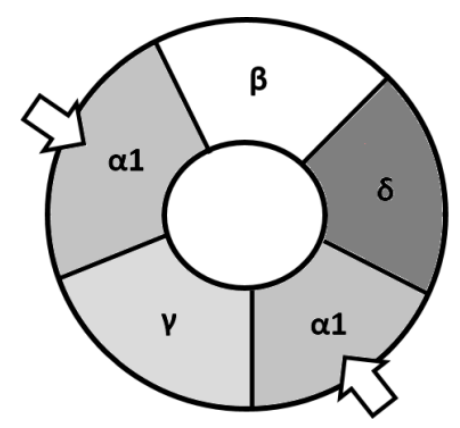

b.

Figure 1. (a) An example of the neuronal-type nicotinic acetylcholine receptor subunit composition for the common (i) $\alpha 7$ homopentameric and (ii) $\alpha 4 \beta 2 *$ heteropentameric subtypes. The ligand binding sites are displayed between alpha subunits (homopentameric) or alpha and beta subunits (heteropentameric). (b) Bâsic five subunit structure of the muscle-type nicotinic acetylcholine receptor with the acetylcholine binding site indicated on the alpha subunits. This example depicts subunits $\alpha, \beta, \delta$ and $\gamma$ in the ratio $2: 1: 1: 1$. 
Table 1. Evidence of neuronal-type nAChR subunit detection and composition in different tissue types- both within and outside the central nervous system.

\begin{tabular}{|c|c|c|}
\hline $\begin{array}{l}\text { Organ/Syste } \\
\text { m }\end{array}$ & Location & $\begin{array}{c}\text { Neuronal Nicotinic } \\
\text { Acetylcholine Receptor Subunits }\end{array}$ \\
\hline \multirow[t]{7}{*}{ Brain } & Unspecified & $\begin{array}{l}\alpha 3, \alpha 4, \alpha 5, \alpha 6, \alpha 7, \beta 2, \beta 3 \& \beta 4 \text { (Maus } \\
\text { et al., 1998) }\end{array}$ \\
\hline & Hippocampus & Mainly $\alpha 7$ (Court et al., 2000) \\
\hline & Cerebellum & $\alpha 3, \alpha 4, \alpha 7 \& \beta 2$ (Court et al., 2000) \\
\hline & Striatum & $\alpha 3, \alpha 4, \alpha 7 \& \beta 2$ (Court et al., 2000) \\
\hline & Substantia Nigra & $\alpha 3, \alpha 4, \alpha 7 \& \beta 2$ (Court et al., 2000) \\
\hline & Cortex & $\alpha 3, \alpha 4^{*}, \alpha 7 \& \beta 2($ Court et al., 2000) \\
\hline & Microglia & $\alpha 7$ (De Simone et al., 2005) \\
\hline Blood Brain Barrier & Brain Endothelial Cells & $\begin{array}{l}\alpha 3, \alpha 5, \alpha 7, \beta 2 \& \beta 3 \text { (Abbrustcato et } \\
\text { al., 2002) }\end{array}$ \\
\hline Heart & $\begin{array}{l}\text { Aortic Endothelial } \\
\text { Cells }\end{array}$ & $\alpha 3 \& \alpha 7$ (Wang et al., 2001) \\
\hline Lung & $\begin{array}{l}\text { Bronchial Epithelial } \\
\text { Cells }\end{array}$ & $\begin{array}{l}\alpha 3, \alpha 5, \alpha 7, \beta 2 \& \beta 4 \text { (Maus et al., } \\
\text { 1998; Wang et al., 2001) }\end{array}$ \\
\hline Muscle & Muscle Fibre (rat) & $\alpha 7$ (Fischer et al., 1997) \\
\hline \multirow[t]{2}{*}{ Immune } & Thymus & $\begin{array}{l}\text { Human- } \alpha 3, \alpha 5 \& \alpha 7 \text { (Navaneetham et } \\
\text { al., 1997; Conti-Fine et al., 2000). } \\
\text { Murine only- } \alpha 2, \alpha 4, \beta 2 \& \beta 4 \text { (Kuo et } \\
\text { al., 2002) }\end{array}$ \\
\hline & $\begin{array}{l}\text { Peripheral } \\
\text { Macrophages }\end{array}$ & $\alpha 7$ (De Simone et al., 2005) \\
\hline Skin & Keratinocytes & $\begin{array}{l}\alpha 3, \alpha 5, \alpha 7, \alpha 9, \beta 2 \& \beta 4 \text { (Grando et } \\
\text { al., } 1995,1996 ; \text { Nguyen et al., 2000) }\end{array}$ \\
\hline
\end{tabular}




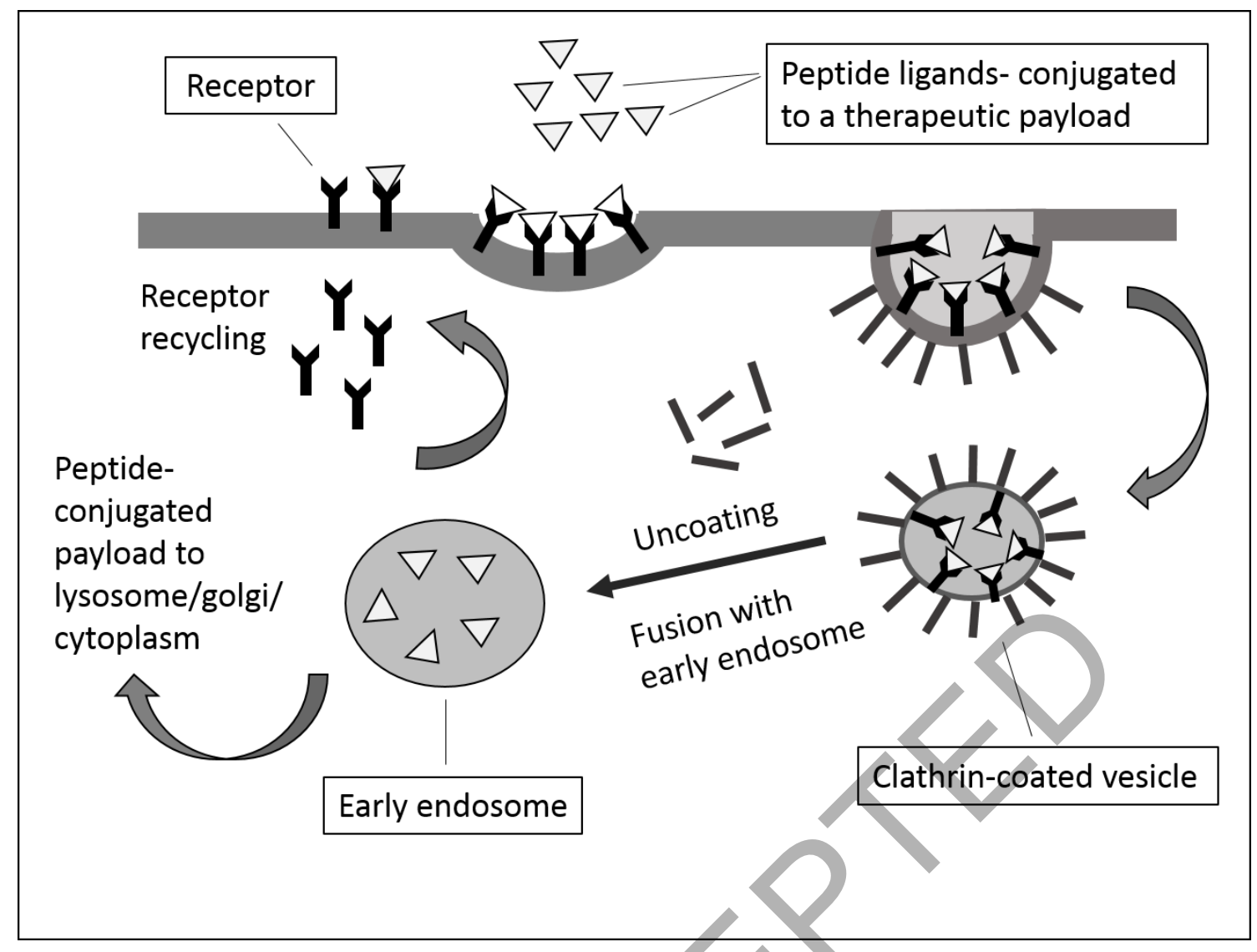

Figure 2. Hypothetical route of uptake of rabies virus-derived peptide (RDP) via clathrin-dependent receptor-mediated endocytosis. 